\title{
MEDIDA E DESMEDIDA \\ na Bahia de Gabriel soares de sousa
}

\section{Francisco Ferreira de Lima}

A vocação pantométrica ${ }^{1}$ do Ocidente estava consolidada ao final do século XVI. E suas marcas estavam por toda parte. No comércio, a contabilidade por partidas dobradas, com seu registro minucioso e sistemático de receita e despesa, tinha posto ordem à barafunda em que vivia o comerciante medieval, cujo sucesso ou fracasso dependia - quando não exclusivamente de sua boa ou má memória - de um amontoado de garatujas no qual, misturadas aos precários dados de compra e venda, podiam-se ler "cronologias de vitórias e derrotas em batalhas, bem como as de eventos sociais", como diz o mesmo Crosby (97: 204). Com a contabilidade por partidas dobradas, o comerciante pôde enfrentar de modo confortável os novos tempos globais, em que as pequenas quantidades tradicionalmente comercializadas cederam lugar às toneladas e as moedas, às letras de câmbio e aos juros.

$\mathrm{Na}$ música, estabelecido que o som era um fenômeno físico movendo-se no tempo, os tempora, foi possível representá-la, atribuindo-se símbolos aos sons, de tal maneira que a música pôde ser "ouvida" antes de ser tocada - mesmo por um surdo, como os tempos vieram depois mostrar com talvez o mais famoso de todos eles. Representada graficamente, a música se permitiu explorar possibilidades inimaginadas

1 Tomo o termo, assim como o seu desenvolvimento apresentado nessa introdução, a Alfred Crosby, que $\mathrm{o}$ analisa em The measure of reality - quantification and western society, 1250-1600. A referência completa encontra-se ao final do texto. 
aos seus cultores medievais, a ponto de o papa João XXII, ainda no distante início de século XIV, informa o mesmo Crosby (97: 159), dar-se ao trabalho de publicar uma proclamação dedicada exclusivamente à música, na qual verbera acerbamente contra a polifonia, por esta "obrigar as vozes a um constante movimento para frente e para trás, que mais intoxica o ouvido que o acalma, levando o ouvinte a substituir a devoção pela frivolidade”. Estava certo o Papa: quantificada, a música nunca mais seria apenas (santa) mezinha para os nervos.

Não era menor a presença da pantometria na pintura. Já muito distante da concepção medieval de espaço, segundo a qual tudo há que estar preenchido, uma vez que o vazio é tão somente uma inaceitável possibilidade, o artista do século XVI era antes de qualquer coisa um geômetra. Há pelo menos duzentos anos, desde o reaparecimento da Geografia de Ptolomeu, que treze séculos antes já mostrara como representar superfícies curvas em superfícies planas, através de uma rede de linhas entrecruzadas de paralelos e meridianos - as latitudes e longitudes -, a pintura aprendeu a quantificar o espaço na tela, através da utilização daquela mesma rede, passo primeiro para a subseqüente descoberta da perspectiva, que pôs - releve-se o jogo de palavras - a arte visual em outro plano.

No que se refere ao tempo, é quase desnecessário referi-lo. O relógio, peça já familiar e obrigatória na área principal de toda cidade européia, pequena que fosse, ali estava a lembrar os moradores - talvez já esquecidos - que o monstro voraz fora domado, pois que sua principal qualidade, que tanto impressionara os homens do Medievo, doutos e não, sua insubstancialidade, fora dividida em unidades simétricas precisas e distintas, verificáveis inicialmente pelo ouvido e logo depois pelo olhar.

E não era outro, mas o olhar, o buscado horizonte da pantometria. Tudo isso, a contabilidade por partidas dobradas, a partitura musical, a rede entrecruzada na tela e o mostrador do relógio davam a ver por antecipação o que jamais se pensou pudesse ser visto. Com ela, podiam-se ver tanto o fluir do tempo como a música tocada antes de tocada; tanto o negócio fechado ainda em aberto como o quadro pintado antes de pintado. Ou seja, a quantificação permitia ver antes o que se veria (e ouviria e ganharia) depois.

Não foi muito diferente com o espaço - embora bem mais complicado. Assim como a partitura ou a projeção de lucro, o mapa, cada vez mais preciso, fez antever o mundo e seu impensável elenco de maravilhas, pois, como aqueles modelos, ele incita a ver antes o que se verá depois. Mas, diferente deles, o mapa obriga a esforço extra, uma vez que é, por excelência, mais que qualquer outro, um modelo suposto no lacunar: 
ele só pode dar a ver o mundo num aminguamento, pálida imagem de sua real fulguração, que requer o olhar in loco para dar-se por inteiro, resultado, diz Affergan (1987), de curiosa aporia: sem o mapa, não se tem a antevisão da fulguração; mas, sem ir à fulguração, não se pode ter o mapa, a antevisão.

Por isso é preciso partir. Pelas duas coisas: para ver, em tempo e espaço reais, a fulguração do mundo, medi-la e torná-la assimilável (mas não tanto como logo se verá) para efeito de apropriação, de uma parte, e, tarefa não menos significativa, realimentar os elementos do mapa, de outra, de maneira a aprimorar a antevisão ali exposta, para que esta continue a ser o que sempre foi: lacunar que seja, inesgotável fonte de desejo.

Apaziguado pela noção recente de que desvendar os segredos do mundo era tarefa bem quista e bem vista aos olhos de Deus, o homem do século XVI entregou-se com volúpia a tal atividade, esquadrinhado freneticamente os escaninhos do mundo. E mais não fez porque mais não havia por fazer, "que, se mais mundo houvera, lá chegara", como bem disse o vate da viagem lusíada, a reafirmar o ufanismo próprio do tempo.

Gabriel Soares de Sousa foi um desses homens. Tendo chegado à Bahia por volta de 1570, já era, quinze anos mais tarde, bem sucedido homem de negócios, dentre os quais podiam ser arrolados engenhos de açúcar, vastas áreas no Recôncavo baiano, além de propriedades em Salvador, onde o seu prestígio o levou à Câmara de Vereadores, à época o mais importante órgão de representação política da Colônia.

Embora tantas realizações possam parecer muito aos temperamentos acomodados dos tempos de agora, não era o bastante para o espírito de aventura renascentista, obcecado pelas novas novidades do mundo. Assim é que, em 1587, achava-se Soares de Sousa em Madri, para onde se deslocara à cata de financiamento para uma expedição às nascentes do São Francisco, que daria seguimento à malograda aventura de seu irmão João Coelho, morto em meio do caminho, com vistas a localizar Vupabuçu, a lagoa mítica dos índios, de onde se acreditava jorrar ouro em pó a céu aberto.

Para vencer a pouca boa-vontade do rei Filipe II - Filipe I de Portugal -, Soares de Sousa lhe oferece um caderno "tirado a limpo", no qual se encontram registradas "muitas lembranças do que me pareceu digno de notar", recolhidas ao longo de "17 anos que residi no estado do Brasil", sem outro objetivo aparente que o de ter sido, diz ele, "obrigado por minha curiosidade", como se pode ler na carta que faz acompanhar o texto ${ }^{2}$.

2 A carta pode ser lida na edição organizada por Francisco Adolfo de Varnhagen - a mesma utilizada ao longo desse estudo, que, por isso, trará a citação do Tratado de Soares de Sousa acompanhada apenas do número da página na qual está inserida. A referência completa encontra-se no final do texto. 
O "caderno" é o que Francisco Adolfo de Varnhagen, depois de laboriosa garimpagem, cujo resultado é sua indiscutível certidão de autoria, intitulou muito apropriadamente de Tratado descritivo do Brasil em 1587.

Dividido em duas partes, a primeira dedicada ao Brasil de modo geral e a segunda, à Bahia em particular, visto, diz ele, as grandezas e maravilhas desta não caberem naquela, o Tratado. traz exaustivo levantamento do Brasil, do Amazonas à "ponta do rio da Prata", num rigoroso exercício de pantometria, de que nada escapa. O efeito, só superado nos tempos modernos, é a mais abrangente compilação de dados corográficos, botânicos e zoológicos - para não falar nos etnográficos, históricos e geográficos - do Brasil em seus primeiros dias.

E tudo, como convém ao curioso homem do Renascimento, visto de vivo olhar, instrumento de tal modo suficiente em Soares de Sousa, que mais de um crítico já fez notar a ausência de referência bibliográfica ao longo de seu texto ${ }^{3}$. É preciso ver para medir e, tão importante quanto, ver para corrigir, de maneira a, como já se disse, aproximar tanto quanto possível a visão da antevisão, assegurando a força da fonte do desejo na reinserção do real em uma agora atualizada ordem do saber:

e ao mar doze léguas da boca desse rio estão ilhas, as quais demoram em altura de um terço de grau da banda do sul. Estas ilhas se mostram na carta mais chegadas à terra, $o$ que é erro manifesto (p. 43) ${ }^{4}$.

Ou seja, se a carta incita a ver, o real visto, por sua vez, obriga o redimensionála, sob pena de ela não ser capaz de oferecer sequer o mínimo prometido: reduzida, mas adequada antevisão do mundo. E o redimensioná-la só se faz possível através do exercício do olhar, que mede, conta, quantifica. e corrige, quando for o caso.

Visto de perto, pois, a fulguração do real ganha configuração. E a carta, sua antevisão, ganha precisão, eliminando-se distância e dissabor entre o antevisto e o visto depois, fundamental mecanismo eliminador de formas várias de desamparo, dentre as quais - e a pior de todas - a desmedida, que desmonta, como numa catástrofe, a utensilagem mental, pacientemente arrumada para defrontar o novo. Vencer a des-

\footnotetext{
3 É o caso, por exemplo, de Américo Jacobina Lacombe, impressionado com o fato de Soares de Sousa não citar fontes ao longo de seu texto, que resultaria, portanto, só e somente de "conhecimento direto".

$4 \mathrm{O}$ destaque em itálico na citação, nesta e nas outras, é meu. Quando não for o caso, chamarei atenção para o fato.
} 
medida é, portanto, o desafio primeiro. Desafio a que o desbravador se entrega prazerosamente, pois, diz ele (p. 44), não bá coisa que se encubra aos homens que querem cometer grandes empresas.

Descobrir, isto é, fazer vir à tona o que está encoberto, é tarefa primeira a que, como ele próprio diz, se obriga o curioso. E quando o a descobrir já o foi, é preciso, que não há limites para a curiosidade, redescobri-lo, posto que nunca se sabe quantas camadas encobertas ainda há por enfrentar, que estão elas em todos os lugares, verdadeiras armadilhas de sentido, sempre a desafiar a competência do observador:

A ponta do leste do rio das Amazonas está em um grau da banda do sul; dessa ponta ao rio da Lama há 35 léguas, a qual está em altura de um grau e três quartos; $e$ ainda que este rio se chame da Lama, podem entrar por ele adentro e estarem muito seguras de todo o tempo, naus de 200 tonéis, o qual rio entra pela terra adentro muitas léguas (p. 45).

Estabelecidas as medidas, trata-se também de operar num nível fundamental, que é o do nome da coisa, sem o que a medida perde sua razão de ser - afinal o cometimento de grandes empresas requer grandeza equivalente em proveito.

Como a desaprovar a noção de arbitrariedade do signo, Soares de Sousa faz seu olhar repor a adequação entre o nome e a coisa. Re-significado pelo trabalho do olhar, o termo lama, agora, descortina um mundo de amplas possibilidades, até então mascaradas naquele nome, ao invés de remeter para seu sentido habitual de podridão e sujeira - e todas as inferências que essas palavras possam produzir. Desbastada a antiga significação, é aproveitar-se da nova, para ir em busca dos tesouros que a outra escondia.

E como se não bastassem os que se expõem a olho nu, é mesmo de tesouros escondidos que se alimenta esse olhar:

Dão-se nestas capitanias [de São Vicente e Santo Amaro] uvas, figos, romãs, maçãs e marmelos, em muita quantidade, e os moradores da vila de São Paulo têm já muitas vinhas; e há homens nela que colhem já duas pipas de vinho por ano (...) e também há já nesta terra algumas oliveiras, que dão fruto, e muitas rosas, e os marmelos são tantos que os fazem de conserva, e tanta marmelada que a levam a vender para as outras capitanias. E não bá dwida se não que há nestas capitanias outra fruta melhor que é prata, o que se não acaba de descobrir, por não ir à terra quem a saiba tirar das minas e fundir (p. 114-5). 
De modo panorâmico, o olhar de Soares de Sousa vagueia, deliciado, por um elenco de elementos familiares, que, não fosse a exuberância da terra a obrigar ao desfazimento do excesso, podia-se bem pensar estar-se ante a realidade da maior de todas as fantasias do viajante, qual seja, a de transplantar para a nova terra a terra antiga - e não apenas o nome como de hábito lhe resta fazer. Diante de frutas tão conhecidas e, ademais disso, tão viçosas, não há dúvida de que a Espanha, uma Espanha viçosa e remoçada, é aqui.

Mas tal vaguear do olhar se adensa e, tal qual o super-herói contemporâneo, que nenhuma barreira o impede de ver, ultrapassa essas camadas do visível, para deter-se numa outra, na qual se esconde ao olhar comum um outro jardim, também este de delícias, melhores e mais reluzentes, virginalmente indevassado, à espera de quem ouse vir colher seus sabores - sabores esses cujos sentidos se alargam se se levar em conta o fato de à prata ser atribuída a condição de fruta melhor que todas as outras.

Como se pode notar, ao olhar que quer ver, nada pode ficar em seu caminho. E quanto mais capaz for na sua tarefa de desvelar o oculto, tanto maior será sua recompensa. Nesse caso, o fruto, se não o proibido, o escondido, que vem a dar quase no mesmo.

Mas nem sempre é tudo tão pacífico assim ${ }^{5}$. Ou, dito de modo mais radical, nunca é tudo tão pacífico assim. Ao defrontar as camadas fulgurantes do real, que, por sua novidade inaugural, estão ausentes de todas e quaisquer modalidades de antevisão, por precisos que sejam os mapas ou quaisquer outras formas de modelização, o projeto pantométrico perde sua razão de ser. O real defrontado ganha uma sobrecarga, ou melhor, um excesso de fulguração que repele toda e qualquer tentativa de apreensão, seja porque método for, que nenhum é bastante para dar conta do que nunca se viu.

Incapaz de pôr ordem nesse excesso, que extravasa todo e qualquer limite que se lhe queira atribuir, a utensilagem mental, com todos os seus dispositivos de medição, quantificação e contagem, queda-se inútil, porque catastroficamente emaranhados. Nada explica nada. Nada justifica nada.

Nesse momento, o olhar ganha autonomia e pode - é mesmo essa a palavra gozar soberanamente o efeito do deslumbramento, resultado - no belo achado de

\footnotetext{
5 A idéia de excesso de fulguração do real, como vai aqui apresentada, foi desenvolvida por Francis Affergan
} em Exotisme et alterité. 
Affergan - de uma cintilação do real, cuja visão é puro êxtase. Agora o viajante, voraz quantificador, é, todo ele, só um olho que vê - prazerosamente. Não é outro senão esse efeito que o viajante tenta traduzir na palavra maravilha, presente em toda narrativa de viagem, por mais objetiva que esta pretenda ser.

Gabriel Soares de Sousa, como todo bom viajante, como todo bom pantômetra, não ficou imune aos encantamentos da cintilação:

Em todo o tempo do ano, quando chove, fazem os céus da Bahia as mais formosas mostras de nuvens de mil cores e grande resplendor, que se nunca viram noutra parte, o que causa grande admiração. E há-se de notar que nesta comarca da Bahia, em rompendo a luz da manhã, nasce com ela justamente o sol, assim no inverno como no verão. E em se recolhendo o sol à tarde, escurece juntamente o dia e cerra-se a noite; a que matemáticos dêem razões suficientes que satisfaçam a quem quiser este segredo, porque mareantes e filósofos que a esta terra foram, nem outros homens de bom juízo não tem atinado até agora com a causa porque isso seja (p. 133).

O tempo chuvoso, que corresponde ao inverno, é, em todas as culturas tropicais, época de (suave) recolhimento interior, levemente - apenas levemente - assemelhado àquele produzido pela chegada do inverno nas zonas frias, em que a neve cobre com seu manto branco as cores do mundo, advertindo que a vida entra em longo compasso de espera, cujo fundamento é a carência de calor, mas também de cor e de olor, que aponta para uma espécie de sono/morte temporária da natureza, quando esta se recolhe para realimentar suas energias.

Por conseguinte, com a chegada das chuvas e seu inverno aquoso, era de esperar que as trevas, na forma de nuvens negras, densas e pesadas, fizessem sua aparição, ainda que timidamente, para marcar a presença desse compasso de espera, em que a vida se manifesta como ausência. Mas o que se tem, pelo contrário, é um redobrar da vitalidade da natureza, que, como para se precaver da ameaça, faz a luz atravessar a sombra da nuvem, que se oferece então como deslumbrante espetáculo de cores, verdadeira (e não mais teórica) cintilação do real, que pode ser flagrado na palavra resplendor.

Espetáculo único - não se pode vê-lo, adverte o autor, em nenhum outro lugar -, sua fruição, só pode se dar na inteireza de sua intensidade em presença, posto que é de olhar, e só de olhar, que se trata. Para tê-lo, tal como é, faz-se necessário vir, vencendo audaciosamente os obstáculos que se lhe antepõe. 
Voyeur da audácia alheia, o leitor haverá de se contentar com hipérboles - as mais formosas, mil cores, se nunca viram - e tartamudeios, que substituem a intensidade da experiência vivida por expressões do tipo grande admiração, precária e imperfeita tradução de que são capazes as poucas palavras utilizadas. Porque muitas também não ajudariam: ante a intensidade dessa luz, não há o que interpretar, só admirar, isto é, entregar-se à festa feita para os olhos.

Não há, pois, como supor ou temer a ameaça da treva, negada mesmo quando sua presença se impõe. E mais não houvesse para dizê-lo, fala - misteriosa, mas iluminadamente por si mesma a presença diuturna do sol, independente de qual seja a estação, que o tempo é todo um, aquele de luz e cor.

Tal mistério, aliás, de o sol dizer presente sempre, pede ciência nova para sua decifração, posto que os discursos tradicionais, sejam os da ordem da especulação, sejam os da técnica, sejam, enfim, os da vida prática, não são capazes de fazê-lo, dada a impossibilidade operacional de alcançá-lo, posto que toda a pantometria volveu-se inútil ante simetria tão precisa e porque precisa, excessiva. Mas aquele a quem quiser embutido no texto de Soares de Sousa parece apontar, não sem uma pequena pitada de ironia, para o fato de ele estar menos interessado na resposta do que no deslumbramento da pergunta, como a levantar uma ponta de suspeita acerca da capacidade da ciência (renascentista) operar uma completa dessimbolização do mundo, na qual o mistério cederá lugar ao medido e quantificado.

E se assim for, parece muito longe o dia em que tal acontecerá, porque, para se onde olhar, parece mais fácil defrontar o primeiro que levar a cabo o segundo:

Das árvores a principal é a parreira, a qual se dá de maneira nesta terra, que nunca lhe cai a folha, se não quando a podam que lha lançam fora; e quantas vezes a podem, tantas dá fruto; e porque duram poucos anos com a fertilidade, se as podam muitas vezes no ano; é a poda ordinária duas vezes para darem duas novidades, o que se faz em qualquer tempo do ano conforme ao tempo em que cada um quer as uvas, porque em todo o ano madurecem e são muito doces e saborosas, e não amadurecem todas juntas; e há curiosos que têm nos seus jardins pé de parreira que tem uns braços com uvas maduras, outros com agraços, outros com frutos em flor e outros podados de novo; e assim em todo ano têm uvas maduras numa só parreira (p. 166).

Dos topoi mais arraigados no imaginário europeu estava o de uma terra, cuja boa temperança do clima, isento de grandes frios e de grandes calores, mantinha tudo 
permanentemente verde. Tal lugar, onde tudo é sempre verde - acreditou a Idade Média e boa parte do Renascimento, que saiu à sua procura - só é possível no paraíso terreal, jardim de delícias inacessível aos homens dado o deslize de seus primeiros pais.

É, antes de tudo, na relação com esse topos que se pode entender o espanto de Soares de Sousa ante a fertilidade milagrosa da Bahia - sem que sejam necessárias ilações acerca da árvore escolhida, a parreira, de tão ampla significação na tradição judaico-cristã. Ao invés da morte anunciada, em que o espaço branco com suas árvores desnudas desenha, de modo angustiante, o cenário da desolação, tem-se, ao contrário, uma natureza tal e qual a do paraíso terreal, onde o homem reina soberano sobre as condições do tempo, fazendo-o dobrar-se à sua vontade: "o que se faz em qualquer tempo do ano conforme ao tempo em que cada um quer as uvas."

Dobrado o tempo, a vida inscreve-se num contínuo marcado pela permanência da verdura, que garante a presença da folhagem, a qual, por sua vez, assegura a vitória sobre a angústia da morte cíclica, anunciada a cada outono, inaugurando-se assim outra dimensão temporal. Nesta, eliminada a brancura da morte, a natureza permanentemente viva pode finalmente substituir a lógica do sucessivo, pela do simultâneo, sendo então possível ter-se tudo ao mesmo tempo e de uma só vez: "e há curiosos que têm nos seus jardins pé de parreira que tem uns braços com uvas maduras, outros com agraços, outros com frutos em flor e outros podados de novo; e assim em todo ano têm uvas maduras numa só parreira."

O tempo, cujo encapsulamento no relógio, lembra, hora a hora, a inexorável marcha para a morte, numa unilinearidade que não conhece desvio, pode outra vez ser vivido como totalidade, da qual estão ausentes os temores da escassez, e, o pior de todos, o do fim porque fim já não há e, por isso, já não há começo e o tempo é todo um. Livres, portanto, desses perigos, e desacostumados a tantos matizes em simultâneo, os olhos podem voltar-se para a festa da natureza, que vive em permanente estado de celebração.

Naturalmente, o gozo do olhar, como todo gozo, é fugidio. A sua soberania não perdura para sempre - embora eterna na sua intensidade. Pouco a pouco, a utensilagem mental começa a recuperar-se da vertigem de que se viu vítima e, como se se estivesse despertando de um sonho bom, o mundo vai ganhando outra vez contornos de objeto exterior e alheio ao corpo que com ele se fundira numa unidade. A fulguração começa lentamente a ceder seu lugar à configuração. Mas, por enquanto, suas fronteiras, tênues e precárias, falam mais de impossibilidades que de certezas estabelecidas: 
Andei buscando até agora onde agasalhar os caranguejos-do-mato, sem lhes achar lugar cômodo, porque para os arrumar com os caranguejos do mar parecia despropósito, pois se eles criam na terra, sem verem nem tocarem água do mar; e para os contar com os animais parece que também não lhes cabia esse lugar, pois se parecem com o marisco do mar; e por não ficarem sem gasalhado nestas lembranças, os aposentei na vizinhança do marisco da terra, ainda que se não criam na água estes caranguejos, mas em lugares úmidos por todas as ribeiras (p. 298).

Desmontado pela variedade não catalogável do real, o método para quantificá-lo há que sofrer adaptação, se se quiser um mínimo de fidelidade na representação desse real rebelde a formas de redução, em outras circunstâncias já provadas tão precisas, como o sejam medir embocaduras de rios e extensões de terras, extensas que sejam. Diante de tantas impossibilidades metodológicas, pode-se tão somente montar um tosco arranjo do que efetivamente está-se a observar, oferecendo-se assim não o que leitor esperaria (e deveria) encontrar, isto é, um elenco organizado e compartimentado das diversas camadas desse real, mas um conjunto cujas fronteiras estão imbricadas - e, ao que parece, a julgar pela decisão de apresentar os caranguejos-do-mato ali mesmo, apesar de tanta explicação, ou mesmo por causa dela, imbricamento que terá sua solução adiada por muito tempo.

Homem de ver, de nomear e de contar, Soares de Sousa sabe, todavia, não lhe restar alternativa nessa dura peleja contra um real inabordável senão continuar a enfrentá-lo. E enquanto não surjam métodos mais precisos que dêem conta de sua até aqui irredutível superposição de camadas, ele há de ser tratado com os instrumentos disponíveis, mesmo que o mais das vezes tanto e ingente esforço possa parecer inútil, uma vez que as medidas do mundo são quase sempre tiradas em meio às pressões e seduções de suas trabalhosas, enganosas e fascinantes desmedidas.

\section{$\operatorname{son} 2$}

\section{REFERÊNCIAS BIBLIOGRÁFICAS}

AFFERGAN, F. (1987). Exotisme et alterité. Paris, PUF.

CROSBY, A. W. (1997). The measure of reality. Quantification and Western society, 1250-1600. Cambridge, Cambridge University press.

DELUMEAU, J. (1984). A civilização do Renascimento. Lisboa, Estampa.

DREYER-EIMBACK, O. (1992). O descobrimento da terra. São Paulo, Edusp/Melhoramentos. 
GILBERT-DUBOIS, C. O imaginário da Renascença. Brasília, UNB.

GODINHO, V. M. (1990). Mito e mercadoria, utopia e prática de navegar - séculos XIII/XVIII. Lisboa, Difel.

HOLLANDA, S. B de (1992). Visão do paraíso. 5ed., São Paulo, Brasiliense.

LACOMBE, A. J. Gabriel Soares de Sousa e o Tratado descritivo do Brasil. In: SOUSA, Gabriel Soares de (1851/1987. Tratado descritivo do Brasil em 1587. São Paulo, Companhia Editora Nacional.

LIMA, F. F. de (2000). A Bahia de Gabriel Soares de Sousa. Quinto Império. 12;(49-73). Salvador, Gabinete Português de Leitura.

LIMA, F. F. de (2000). O olhar que não vê: Gabriel Soares de Sousa e a permanência do fantasioso. In: FONSECA, A. \& PEREIRA, R. A. (Orgs.). Rotas e imagens - literatura e outras viagens. Feira de Santana, UEFS/PPGLDC.

SOUSA, Gabriel Soares de (1851/1987). Tratado descritivo do Brasil em 1587. São Paulo, Companhia Editora Nacional, col. Brasiliana, vol. 117. (Edição castigada pelo estudo e exame de muitos códices manuscritos existentes no Brasil, em Portugal, na Espanha e França, e acrescentada de alguns comentários por Francisco Adolfo de Varnhagen.)

Francisco Ferreira de Lima é Professor Titular de Literatura Portuguesa na UEFS. Graduado em Letras pela UFBA, Mestre pela PUC/Rio, Doutor pela USP e Pós-Doutor pela University of London - King's College. É autor de O outro livro das maravilhas: A Peregrinacão de Fernão Mendes Pinto (Rio de Janeiro, Relume Dumará, 1998) e co-editor de $A$ cor das letras e editor de Légua \& meia. 